\title{
Do enunciável ao visível: as condições de possibilidade do videopoema "Vida em Branco"
}

\author{
From the enunciable to the visible: the possibilities' conditions of the video poem \\ Vida em Branco
}

\author{
Antônio FERNANDES JÚNIOR \\ Universidade Federal de Goiás, Regional Catalão (UFG/RC) \\ https://orcid.org/0000-0002-4969-0407 \\ Amanda Soares MANTOVANI \\ Universidade Federal de Goiás, Regional Catalão (UFG/RC)
}

https://orcid.org/0000-0002-3379-3778

\begin{abstract}
RESUMO: Com o objetivo de discorrer e refletir sobre os procedimentos de análise advindos da filosofia de Michel Foucault, especialmente esses que estão contemplados em sua obra "A Arqueologia do Saber" (1969), este trabalho abrange uma discussão voltada para as contribuições do pensamento foucaultiano aos estudos da linguagem, diante da necessidade de se mobilizar uma atitude histórico-crítica sob o objeto em análise. Para tanto, o percurso aqui adotado desenvolve-se sob a perspectiva arqueogenealógica, apoiando-se em estudos desenvolvidos pelo próprio Foucault $(1999,2005 a, 2005 b, 2014,2016,2017)$ e em obras de Deleuze (2017, 2019), Veyne (2009), Gregolin (2004, 2006), entre outros autores. Ao explanar sobre a noção de discurso e enunciado, o discursivo e não discursivo, tentamos descrever, ao fim, como pensar sobre uma história crítica do pensamento proporciona vislumbrar as condições de emergência que possibilitam determinados acontecimentos discursivos, a exemplo, o videopoema de Zélia Duncan, "Vida em Branco" (2020).
\end{abstract}

PALAVRAS-CHAVE: Dispositivo. Discurso. Michel Foucault. Arqueologia. Arte.

ABSTRACT: To discuss and reflect on the analysis procedures which came from Michel Foucault's philosophy, especially those which are included in his work The Archeology of Knowledge (1969), this article includes a discussion focused on the contributions of Foucaultian thought to the language studies, in the face of necessity to mobilize a historical-critical attitude under the aim in the analysis. For this purpose, the way chosen here develops under the archeogenealogical perspective, based on Foucault's researches (1999, 2005a, 2005b, 2014, 2016, 2017) and in works by Deleuze (2017, 2019), Veyne (2009), Gregolin (2004, 2006), among other authors. When explaining the notion of discourse and statement, the discursive and nondiscursive, we tried to describe, in the conclusion, how to think about a critical history of thought that provides to see the emergency conditions which make possible certain discursive events, for example, the video poem by Zélia Duncan, Vida em Branco (2020).

KEYWORDS: Device. Discourse. Michel Foucault. Archeology. Art.

\section{Introdução}

Apoiando-se nas ferramentas de abordagem traçadas por Michel Foucault, especialmente nas que foram construídas no livro "A Arqueologia do Saber" (2016), e 
por se tratar de um tipo de procedimento que investiga e pormenoriza uma proposta de análise arqueológica dos discursos, tem-se a descrição de enunciados, das redes discursivas, e o estudo das práticas sociais como uma proposta metodológica muito potente, sobretudo naquilo que diz respeito às relações e implicações entre discurso e história. Destarte, as contribuições deste livro ao campo dos estudos discursivos têm sido objeto de profundas reflexões em grupos de pesquisa espalhados pelo Brasil ao longo dos anos, o que pode ser vislumbrado, por exemplo, na criação do GT Estudos Discursivos Foucaultianos, vinculado à Associação Nacional de Pós-Graduação e Pesquisa em Letras e Linguística (ANPOLL), não apenas pela criação do grupo em si, mas pela inserção e visibilidade dos estudos foucaultianos e das respectivas contribuições no domínio dos estudos da linguagem.

Nesse sentido, múltiplas são as possibilidades e inquietações acerca dessa filosofia que coloca a linguagem em outro plano, dentro de uma dimensão semiológica, num território das possibilidades e das (des)continuidades da trama discursiva, a qual não se delimita, exclusivamente, pelos fatos linguísticos, abrindo um campo propício para a análise de distintas materialidades, sejam elas verbais, não verbais ou verbovisuais. Como é de conhecimento dos apreciadores dos pensamentos de Michel Foucault, o referido livro se define como momento de passagem dos estudos desse autor a outro período de suas pesquisas, pois, ao refletir sobre as produções precedentes, oferece explicações metodológicas sobre elas e abre o caminho para os estudos genealógicos, que serão dedicados à problematização da analítica do poder, período no qual a abordagem dos dispositivos de poder e de demais conceitos entra em cena ${ }^{1}$.

Sob esse segmento, almejamos refletir de que forma o livro supramencionado, publicado incialmente em 1969, já apresenta em seus apontamentos passagens para a noção de dispositivo e os contínuos jogos de saber-poder que se lançam sobre os objetos, de forma a constituí-los e a moldá-los. Em seguida, pretendemos discorrer sobre as imbricações discursivas e não discursivas (enunciável e visível) que objetivaram a noção de arte entre o final de 2019 e o início de 2020, de modo a proporcionar uma conversão do olhar sob o objeto de análise, num gesto de descrever e problematizar o texto "Vida em branco" (2020), de Zélia Duncan, enquanto acontecimento discursivo, a partir do qual emergiram questionamentos sobre o lugar da

\footnotetext{
${ }^{1}$ Essa divisão, em três momentos, dos estudos de Michel Foucault, como é bastante conhecida e difundida, cumpre uma função didática, pois os deslocamentos e revisões teóricas realizadas por esse filósofo não se limitam a um período ou a outro.
} 
arte na atual conjuntura política brasileira. Ao final desta discussão, faremos uma reflexão sobre as contribuições dos apontamentos foucaultianos para os estudos da linguagem, buscando indicar uma perspectiva arqueogenealógica de análise de discursos.

\section{Do enunciado ao domínio coerente de descrição}

Inicialmente, quando se discute o enunciado, visto como conjunto de signos com modalidade específica de existência, faz-se necessário observar os caminhos pelos quais Michel Foucault buscou definir as regras capazes de apreender como tal série de signos pode adquirir certa função enunciativa. Entre as ponderações, constata-se a importância dos códigos (língua) na sua espessura material, o que Gregolin (2006, p. 89) afirma ser "um sistema de construção para enunciados possíveis". Necessita também, de certa substância e suporte (físico, onde os enunciados se alojam, ou institucional, que os abriga e os legitima), bem como de um veículo, lugar ou data. Entretanto, não se pode limitar o enunciado a componentes linguísticos, mas sim, questionar "esse modo singular de existência" (FOUCAULT, 2016, p. 106) a partir do momento em que uma série de signos é enunciada e passa à condição de algo efetivamente produzido, adquirindo status de enunciado, seja tomando forma em propagandas, gravuras, charges, pinturas, corpo, gestos ou na própria arte.

Para além da substância, "um conjunto de signos em função enunciativa" (GREGOLIN, 2004, p. 26) está inserido em um espaço de correlações, visto que "é no interior de uma relação enunciativa determinada e bem estabilizada que a relação de uma frase com seu sentido pode ser assinalada" (FOUCAULT, 2016, p. 109). Assim, a partir da relação enunciativa, observar-se-á, no momento de análise, os campos associados, as "margens povoadas de outros enunciados" (FOUCAULT, 2016, p. 118) e as tramas discursivas postas em jogo sobre artistas que questionam determinados padrões normativos não aceitos pelas práticas políticas do atual governo, como é o caso do presente estudo. Não se trata, porém, de um alguém ou de coisas específicas, mas de condições, de leis de possibilidade de emergência, de relações passíveis de serem descritas, negadas, afirmadas, refutadas. É sobre esse referencial que recai a possibilidade de atribuir ou não sentido a certo sintagma, caracterizando-o em um particular nível enunciativo com condições singulares de existência, afastando da ideia de significante e significado ou de um referente da proposição. 
Nota-se também, além dos dados já indicados, mais características decisivas da função enunciativa, pois mantém relação com um sujeito que não é o autor de um texto ou de uma formulação. O sujeito discursivo está relacionado a uma posição vazia que pode ser ocupada por indivíduos distintos, por meio de um conjunto de possibilidades e sob certas condições e requisitos. Essas regras definem quem pode ou não ocupar a posição-sujeito e assumir um dado enunciado. Por consequência, as posições de sujeito estão intrinsecamente ligadas às formações discursivas e sequências enunciativas, já que, conforme Foucault (2016, p. 116), “esse lugar é uma dimensão que caracteriza toda formulação enquanto enunciado, constituindo um dos traços que pertencem exclusivamente à função enunciativa e permitem descrevê-la”. Desse modo, relações são estabelecidas, a função enunciativa é passível de atualizações e as posições-sujeito são variadas.

É possível distinguir o enunciado ainda, retomando as dimensões do campo associado, citado anteriormente. A frase, a proposição e os acts speeches deixam de ter um autor específico no instante em que o nível enunciativo abrange uma série de outras formulações possíveis, um domínio associado que lhe confere status e lugar, que lhe permite ser reformulado, reatualizado; permite criar relações com outras formulações, podendo ser apagado ou recuperado por elas e, por fim, que esteja inserido em uma formação discursiva. Nas palavras de Foucault (2016, p. 121), "não há enunciado que não suponha outros, não há nenhum que não tenha, em torno de si, um campo de coexistências", inserido, portanto, em um jogo enunciativo.

Diante disso, o produto de todas essas particularidades confere ao enunciado uma singularidade, cuja característica remete ao que Foucault considerava importante para se pensar em uma série de códigos que obtém modalidade singular de existência: “como apareceu um determinado enunciado, e não outro em seu lugar?" (FOUCAULT, 2016, p. 33). Talvez, nesse ponto, seja possível afirmar que o acontecimento discursivo se faz presente quando um enunciado adquire status e lugar; quando ocupa um papel no discurso, a partir de regras e de possibilidades que permitem e negam que indivíduos diferentes ocupem certa posição de sujeito, o tipo de objetos a que se dirige e os enunciados com os quais se relaciona (FOUCAULT, 2014).

O acontecimento é, pois, uma dispersão, e é por conta dessas multiplicidades que seguir um princípio de linearidade para uma análise discursiva não é suficiente. A proposta de Foucault, especialmente mencionada ao longo de uma série de pontuações 
sobre a descrição dos enunciados, indica uma dedução por meio de círculos concêntricos como forma de se pensar nas várias dimensões dos enunciados.

Não procedo por dedução linear, mas por círculos concêntricos, e vou ora na direção dos mais exteriores, ora na dos mais interiores: partindo do problema da descontinuidade no discurso e da singularidade do enunciado (tema central), procurei analisar, na periferia, certas formas de grupamentos enigmáticos; mas os princípios de unificação com que me deparei, e que não são nem gramaticais, nem lógicos, nem psicológicos e que, por conseguinte, não podem referir-se nem a frases, nem a proposições, nem a representações, exigiram que eu voltasse para o centro, ao problema do enunciado e que tentasse elucidar o que é preciso entender por enunciado (FOUCAULT, 2016, p.140).

Há uma possibilidade de análise na qual se observa o enunciado como acontecimento discursivo, tanto em sua existência particular, de raridade, quanto em sua exterioridade e pelas relações discursivas que o sustentam e que lhe dão suporte; é o que o filósofo define como um "domínio coerente de descrição" (FOUCAULT, 2016, p. 140). Buscando mais algumas pontuações sobre a noção de círculos concêntricos, verificamos que, em "As palavras e as coisas" (1999), o filósofo francês, ao discorrer sobre As quatro similitudes e, pontualmente, sobre a emulação, afirma:

O semelhante envolve o semelhante, que, por sua vez, o cerca e, talvez, será novamente envolvido por uma duplicação que tem o poder de prosseguir ao infinito. Os elos da emulação não formam uma cadeia como os elementos da conveniência: mas, antes, círculos concêntricos, refletidos e rivais (FOUCAULT, 1999, p. 29, grifo nosso).

Logo, as múltiplas dimensões abarcadas por esses círculos fazem notar a impossibilidade da irrupção de um enunciado isolado, em vista de sua relação constante com um campo adjacente e com as próprias formulações. Diante disso, Foucault pondera que a dedução linear da história tradicional, 'homogênea' e 'contínua', exclui diversas multiplicidades existentes e acontecimentos, "em benefício das estruturas fixas" e que, em contrapartida, "a história do pensamento, dos conhecimentos, da filosofia, da literatura, parece multiplicar as rupturas e buscar todas as perturbações da continuidade" (FOUCAULT, 2016, p. 6-7).

Sendo assim, expõe que alguns questionamentos surgem em razão de se pensar a história e as irrupções dos acontecimentos discursivos, tais como: "que estratos é preciso isolar uns dos outros? Que tipo e que critério de periodização é necessário adotar para cada um deles? Que sistema de relações [...] pode ser descrito entre eles?" (FOUCAULT, 2005a, p.83). Em vista disso, buscar a irrupção dos enunciados em meio 
às dispersões e questionar seu aparecimento, analisar suas relações "(hierarquia, dominância, estratificação, determinação unívoca, causalidade circular)" (FOUCAULT, 2005a, p. 83), investigar as regras de possibilidade que marcam as posições-sujeito, constituem um complexo procedimento que 'escava' os discursos e debruça um olhar cuidadoso sobre os acontecimentos discursivos de uma dada racionalidade histórica, de um arquivo.

Esse gesto requer uma conversão do olhar que seja capaz de buscar explicitar quais discursos e dispositivos de poder foram acionados, pois implica colocar a linguagem num plano em que apareçam as descontinuidades/rupturas e explorar a não linearidade histórica. De certa forma, essa perspectiva arqueológica que possibilita cartografar a captura e a constituição constante dos sujeitos pelos discursos, pelas práticas e jogos de saber-poder, coloca a linguagem em um campo que é diretamente relacionado com a exterioridade, com a história-memória e com as instâncias do discurso, do acontecimento enunciativo.

Especialmente acerca dos círculos concêntricos, Deleuze (2019) explica as três possíveis fatias do espaço que constituem o enunciado, indo do nível mais singular às extremidades e vice-versa. O espaço colateral, ou associado, refere-se ao primeiro nível, o qual compreende outros enunciados que fazem parte desse mesmo grupo. Aqui, nota-se a transversalidade como característica imanente ao enunciado, assim como a constante capacidade de "passar de um sistema ao outro", de forma a nunca permanecer em um, exclusivamente (DELEUZE, 2019, p. 16). Em consequência, faz-se pensar na enunciabilidade como multiplicidades ${ }^{2}$, afastando-se, mais uma vez, de estruturas e sistemas dos atos de fala, das frases e das proposições.

À medida que o espaço colateral marca a relação do enunciado com outros, a segunda fatia, o espaço correlativo, representa a relação dele com outras noções que envolvem o jogo discursivo: as posições de sujeito, os objetos e os conceitos. Desse modo, a conversão do olhar, que viabiliza a percepção e análise de enunciados por suas dimensões, de sua singularidade e relação com os demais componentes da ordem discursiva, faz surgir também um nível que envolve o que é extrínseco às sequências enunciativas, o espaço complementar. Esse espaço de formações não discursivas comporta "instituições, acontecimentos políticos, práticas e processos econômicos"

\footnotetext{
2 Deleuze (2019, p. 17) define o enunciado a partir da concepção de multiplicidade, sobretudo, ao distanciá-lo de uma estrutura ou sistema, especificando que tanto "um enunciado" quanto "uma família de enunciados, formação discursiva, segundo Foucault, define-se antes de mais nada por linhas de variação inerente ou por um campo de vetores que se distribuem no espaço associado".
} 
(DELEUZE, 2019, p. 20); constitui "o limite, o horizonte sem o qual" essas posiçõessujeito e objetos não apareceriam "dentro do próprio enunciado" (DELEUZE, 2019, p. 21). Assim, o não discursivo age como suporte, ora institucional, político, ora das diversas práticas, mas de forma a exercer enquanto gatilho, como dispositivo capaz de articular e formar relações, nomes, formas de agir e de se relacionar, de constituir saberes.

Em suma e em diálogo com Foucault, entende-se a conversão do olhar como um gesto crítico que deve ser lançado sobre os discursos de modo a apreendê-los e analisálos em sua singularidade, pois os enunciados não estão ocultos e nem totalmente visíveis, ou, às vezes, já estão tão 'entranhados' no social que não os identificamos, exigindo um processo de desnaturalização. Essa postura interpretativa implica que a emergência de um dado objeto, independentemente da materialidade que o constitui, não se separa das molduras formais (discursos, enunciados, práticas discursivas, leis etc.) que chegam até nós e que nos cingem (FERNANDES JÚNIOR, 2016).

Em algumas passagens do livro A Arqueologia do saber (2016), o autor já traz indicações sobre a analítica do poder, ao demonstrar que:

[...] o discurso aparece como um bem - finito, limitado, desejável, útil - que tem suas regras de aparecimento e também suas condições de apropriação e de utilização; um bem que coloca, por conseguinte, desde sua existência (e não simplesmente em suas "aplicações práticas"), a questão do poder; um bem que é, por natureza, o objeto de uma luta, e de uma luta política (FOUCAULT, 2016, p. 147-148).

Essa citação reforça os apontamentos anteriores, dentre os quais se destaca uma observação sobre os discursos como objeto de luta e disputa política, que envolvem jogos de saber-poder, vislumbrando-se as relações entre os enunciados e as instituições, ou entre as visibilidades e as dizibilidades de cada racionalidade histórica, sempre atravessadas por esses jogos que possibilitam a produção de enunciados e discursos, inscritas em práticas discursivas e não discursivas que, conjuntamente, incidem sobre os posicionamentos dos sujeitos.

\section{A noção de dispositivo e a constituição dos objetos}

Seriam, então, os dispositivos, marcados exclusivamente pelo não discursivo? Albuquerque Júnior (2017, p. 9) esclarece que, ao contrário, são conjuntos de relações, práticas sociais, discursivo e não discursivo, dito e não dito, instituições, ideologias etc., tudo, "articulado e em funcionamento em dada situação histórica precisa, com objetivos e estratégias", também específicas, mas passíveis de serem descritas. Dessa forma, a 
própria ideia de cartografia seria atraída, já que "analisar um dispositivo requereria a figura de intelectual aranha" (ALBUQUERQUE JÚNIOR, 2017, p. 9); o qual busca nos nós do tecido discursivo, além de 'escavar', a constituição de dada posição-sujeito, as formas do objeto, a constituição histórica e todas as suas imbricações de espaço complementar, construindo 'sua teia' em forma de cartografia.

Desse modo, mesmo que em "A Arqueologia do Saber" o filósofo francês estivesse preocupado com o problema metodológico, com o funcionamento do discurso, com a episteme, vê-se a abertura para a noção de dispositivo atrelada às "dificuldades descritas na arqueologia e à conseguinte introdução da análise do poder" (CASTRO, 2016, p. 124). Logo, pensar o discurso, a enunciabilidade e a análise de suas camadas lança luz sobre outros aspectos imanentes às tramas discursivas, como é o caso das relações com o que é institucional, o que forma o objeto, o não discursivo, ou seja, com todo o conjunto de práticas inter-relacionadas, nas quais o autor não trabalha com causa e efeito, consequência ou finalidade. São, portanto, relações interligadas que se pressupõe, e indicam um processo de dupla captura (DEELEUZE, 2019), no qual não se separa "o lado de dentro do lado de fora dos enunciados" (FISHER, 1996, p. 116), pois os domínios não discursivos fazem parte das condições de emergência dos enunciados ${ }^{3}$. Nas palavras de Deleuze (2019, p. 20),

Uma instituição comporta ela mesma enunciados, por exemplo, uma constituição, uma carta, contrato, inscrições e registros. Inversamente, os enunciados remetem a um meio institucional sem o qual os objetos surgidos nesses lugares do enunciado não poderiam ser formados, nem o sujeito que fala de tal lugar (por exemplo, a posição do escritor numa sociedade, a posição do médico no hospital ou em seu consultório, em determinada época, e o surgimento de novos objetos).

Ao tratar da formação dos objetos, em “A Arqueologia do Saber” (2016), Foucault explicita, por exemplo, que os discursos sobre a loucura, produzidos por diferentes campos de saber (justiça penal, religioso, médico, psiquiátrico, dentre outros), delimitaram a emergência de 'diferentes 'loucuras', como objeto do discurso psiquiátrico" (FOUCAULT, 2016, p. 51). Esse argumento demonstra como os discursos são atravessados por distintos campos de saber e relações de poder que os classificam, delimitam, nomeiam e constroem os objetos de que falam ou podem falar.

\footnotetext{
${ }^{3}$ Embora não se tenha realizado uma busca exaustiva, no livro Arqueologia do Saber, a inter-relação entre o discursivo e o não discursivo pode ser observada pelo número de ocorrências das expressões: "práticas não discursivas" (p. 75, 177, 202), “domínios não discursivos” (p. 182, 183), "sistemas não discursivos" (p. 183) e "campo não discursivo" (p. 76).
} 
Michel Foucault (2016, p. 55) pondera sobre as relações existentes entre "instituições, processos econômicos e sociais, formas de comportamentos, sistemas de normas, técnicas, tipos de classificação, modos de caracterização" e a constituição dos objetos, ressaltando que, por mais que esse não fosse um ponto a desenvolver naquele momento, estavam presentes e tinham influência. Esse sistema coloca em jogo o não discursivo e organiza a constituição externa do objeto, situando-o "em um campo de exterioridade" (FOUCAULT, 2016, p. 55). São relações que estão "no limite do discurso", entre o discursivo e o não discursivo, pois explicita os objetos possíveis de que se pode falar e determinam as condições para que se possa falar, nomear ou classificar tais objetos numa racionalidade histórica específica e, mais, "essas relações caracterizam não a língua que o discurso utiliza, não as circunstâncias em que ele se desenvolve, mas o discurso enquanto prática” (FOUCAULT, 2016, p. 56).

Pensando nisso, buscamos averiguar, primeiramente, de que maneira, a teoria da multiplicidade, descrita e citada por Deleuze e Guattari ao longo de suas obras e presente também nas reflexões de Foucault, sugere a instauração da noção de dispositivo já na 'fase' arqueológica do discurso. Sobre essa associação, Orlandi (1987, p. 42) aponta como esse princípio que recorre ao entrelugar aciona uma percepção que reflete acerca do "lugar em que as coisas ganham velocidade"; ou seja, refere-se, antes, às "linhas e dimensões que ela [multiplicidade] comporta em 'intensão' " (DELEUZE; GUATTARI, 2012, p. 28). Assim, os enunciados, vistos como multiplicidades, reforçam a compreensão de que "apreendemos cada vez um real que não é o mesmo" (VEYNE, 2009, p. 60): a sucessividade dos discursos possibilita pensar o objeto de forma particular, mas não significa que essa objetivação seja rígida ou imutável. Em outras palavras, o aparecimento dos objetos depende de condições históricas específicas, por envolver uma época e todas as circunstâncias que engloba, e de relações discursivas e não discursivas, que compõem o arquivo de um dado período, ou seja, a lei do que pode ser dito.

Estaria Foucault, ao refletir sobre suas pesquisas, esboçando, sem nomear, o conceito de dispositivo? Por ser um livro de passagem e deslocamentos das pesquisas do autor, essa questão já traz em si a resposta, pois, se os enunciados estabelecem conexões e pontos de contato entre distintas discursividades e práticas, a Arqueologia já explorava a perspectiva da multiplicidade, que pode ser vislumbrada a partir de algumas expressões, tais como, "multiplicidades de enunciados", "multiplicidades de registros", “espaço de dissenções múltiplas”, “efeito multiplicador”, “conjunto cerrado de relações 
múltiplas", "espaço de dispersão", dentre outras, conforme a leitura de Orlandi (1987, p. 33). Essa abertura à multiplicidade, às conexões com discursos e outras práticas indica os deslocamentos para as discussões sobre a analítica do poder.

Se o enunciado é a unidade mínima da análise arqueológica, por que não o seria na análise dos dispositivos no período genealógico? Como apreender a rede que se estabelece entre discursos heterogêneos entre si em um dado dispositivo? Se os discursos são imanentes aos dispositivos, e o enunciado é a unidade mínima de análise do discurso, então essa será a ferramenta metodológica a partir da qual apreenderemos as funções sujeitos, os processos de subjetivação e as conexões com discursos e dispositivos de poder (FERNANDES JÚNIOR, 2016, p. 55).

Por conseguinte, os estratos, ou formações históricas, abarcam o enunciável e o visível, de forma a deterem em si formas e substâncias, definindo conteúdo e expressão, locais de dizibilidade e visibilidade. A se pensar na "História da Loucura na Idade Clássica" (1978), por exemplo, Deleuze (2019) elucida sobre como há nos estratos coisas e palavras, e que, neste momento dos estudos de Foucault, o asilo enquanto conteúdo da forma, coisa, tornava-se "lugar de visibilidade da loucura [substância] ao mesmo tempo que a medicina [expressão da forma] formulava enunciados fundamentais sobre a 'desrazão'.” (DELEUZE, 2019, p. 53).

Desse modo, o não-discurso, as visibilidades, estariam mais relacionadas com formas de luz que permitem que objetos e coisas surjam como faíscas, "reverberações" (DELEUZE, 2019, p. 57). No caso, por sua vez, das prisões moldadas pelo panoptismo, há feixes de luz que se lançam às zonas periféricas, tornando quem observa opaco e distribuindo os encarcerados. Em vista disso, a história, sob a perspectiva filosófica de Foucault, compreende não uma linearidade de fatos, mas é capaz de contemplar as descontinuidades, regularidades dos campos de enunciável e visível, práticas discursivas e não discursivas, discursos e instituições, processos econômicos e legislativos, ditos e não ditos que tornam possíveis comportamentos, ideias, condutas, conceitos e saberes. "Cada formação histórica vê e faz ver tudo o que pode, em função de suas condições de visibilidade, assim como diz tudo o que pode, em função de suas condições de enunciado", conforme a leitura de Deleuze (2019, p. 63). De forma mais diluída, a arqueologia é o "agenciamento do visível e do enunciável como constitutivos da formação histórica. É isso que Foucault chamará, na sua terminologia própria, um dispositivo" (DELEUZE, 2017, p. 37). 
Foi pensando nesses procedimentos de investigação que recorrem à "reconstrução histórica das formações discursivas" (COURTINE, 2013, p. 22) e nas consecutivas contribuições de "A Arqueologia do Saber" aos estudos da linguagem que nos inquietou a atual conjuntura na qual determinados segmentos de produção artística brasileira vêm enfrentando e sendo alvos de constantes ataques, tanto por meio de notícias falsas quando pela censura ou discursos de ódio.

\section{Arte, Artivismo: "você não precisa de artistas?!"}

No Brasil, desde que a candidatura oficial de Jair Messias Bolsonaro foi lançada ao público, em 2018, entre muitos posicionamentos polêmicos em relação a diversos setores e temas, incluindo comentários homofóbicos, racistas, machistas, misóginos e xenofóbicos, a arte também foi alvo de críticas, foco de futuras alterações abruptas. Essa desenvoltura, tanto de Bolsonaro quanto de seus apoiadores (o bolsonarismo), permaneceu após a efetivação de sua nova ocupação do posto de presidente, ainda gerando manifestações nas mídias, eventos e ruas.

No início de 2019, o Ministério da Cultura (MinC) foi extinto, tornando-se Secretaria Especial da Cultura, e parte do Ministério do Turismo. Já no dia 24 de abril de 2019, a Lei Rouanet, que fora tão especulada no ano anterior, passou a ser nomeada como Lei de Incentivo à Cultura, cujas particularidades foram reformuladas ${ }^{4}$. Com a alteração e alguns 'reajustes', diversos artistas saíram em defesa da cultura, das artes, da diversidade e do acesso. Além disso, no dia 22 de janeiro de 2020, em um vídeo que circulou nas mídias sociais com a intenção de divulgar sobre o Prêmio Nacional da Cultura, o até então secretário Nacional da Cultura, Roberto Alvim, aparece parafraseando Joseph Goebbels, ministro da Propaganda de Adolf Hitler ${ }^{5}$. Poderíamos estender, ainda, explanando sobre as posses e destituições incessantes para o cargo de secretário(a) Especial da Cultura, que geraram mais desconforto e dúvidas acerca da solidez desse setor, corroborando o discurso de que as propostas artísticas, com performances e temas ligados a diversidade étnica, sexual e social, não têm lugar no atual governo.

\footnotetext{
${ }^{4}$ Algumas pontuações sobre as alterações podem ser consultadas em "Lei Rouanet: o que muda com as novas regras impostas por Bolsonaro", por CartaCapital. Disponível em: <https://www.cartacapital.com.br/cultura/lei-rouanet-entenda-o-que-muda-na-nova-lei-de-bolsonaro/>.

${ }^{5}$ Para mais informações, acessar "Governo suspende edital anunciado por Alvim em vídeo com citação nazista", por Revista Veja (On-line). Disponível em: <https://veja.abril.com.br/politica/governosuspende-edital-anunciado-por-alvim-em-video-com-alusao-nazista/> .
} 
Ao recuar um pouco na história recente, sobretudo no período anterior às eleições presidenciais de 2018, e principalmente, ao período pós golpe de 2016 que destituiu a ex-presidenta Dilma Rousseff, pode-se vislumbrar a emergência de ataques a várias exposições (Queermuseu, em 2017; performance $L a$ Bête ${ }^{6}$, no Museu de Arte Moderna, em 2017) e a artistas que se identificaram, e se identificam, com linha de pensamento mais progressista, dentre eles, Chico Buarque, Caetano Veloso, Gilberto Gil e Zélia Duncan. Esses ataques se sustentaram a partir de discursos que os vinculam à difusão da pedofilia, pornografia e, como consequência, tais grupos se valem de modos de existência de sujeitos defensores do modelo de família heteronormativa, de um discurso de valorização da identidade nacional e dos valores cristãos.

Tais artistas, alvos das críticas do bolsonarismo, são acusados de comunistas, corruptos e/ou 'petralhas' que 'mamam nas tetas do governo', via recursos da Lei Rouanet, destinada a fomentos de projetos artístico-culturais por meio da captação de recursos de empresas. Trata-se de discursos de ódio que são produzidos com um fim específico e com objetivo de "estigmatizar, escolher e marcar um inimigo, manter ou alterar um estado de coisas, baseando-se numa segregação. Para isso, entoa uma fala articulada, sedutora para um determinado grupo, que articula meios de opressão" (SCHÄFER; LEIVAS; SANTOS, 2015, p. 147). São práticas marcadas pelo discurso binário, sustentadas por enunciados de uma rede discursiva que separa os sujeitos por suas posições políticas, criando divisões e separações, estabelecendo a proteção dos 'cidadãos de bem' do resto da população.

Toda essa movimentação em torno da arte no país é pertinente para a presente discussão, cujo enfoque se propõe a problematizar em que condições de possibilidade alguns enunciados de ataque à arte e aos artistas circularam e ainda circulam no meio social. Entendemos as práticas descritas acima enquanto práticas discursivas e não discursivas, já que aquelas detêm uma memória específica, capturam, recorrem a formações discursivas, provocam práticas que resistem a certos discursos e constituem um jogo que, marcado pelo poder, "produz coisas, forma saber, produz discurso" (FOUCAULT, 2017, p. 45); enquanto essas são do âmbito institucional, como as alterações legislativas, partidos políticos e organizacionais dos Ministérios.

\footnotetext{
${ }^{6}$ Para maiores informações, consultar os estudos de Stafuzza e Abrahão (2019) e Fernandes (2019), em Cartografias do contemporâneo: dispositivo, verdade e processos de subjetivação (2019), de Fernandes Júnior e Franceschini. O primeiro estudo se debruça sobre os ataques de políticos ao espetáculo La Bête e o segundo discute a censura às produções La Bête, em 2017, e outras produções que também sofreram ataques e foram alvos de discursos de ódio.
} 
Os enunciados que compõem e/ou formam esses discursos de ódio estão diretamente ligados aos processos econômicos (Lei Rouanet e demais processos de financiamento a projetos culturais) e aos partidos e movimentos políticos (MBL, PSL, PSC e seguidores). Nesse sentido, os enunciados se reportam a essas instituições, ganham um suporte institucional e remetem a esses espaços, constituindo o dentro e o fora do enunciado. Contudo, não significa que tais instituições estão à parte e nem que são alheias aos discursos, mas os constituem e especificam as condições para o "campo de dizibilidade", para o enunciável (DELEUZE, 2019, p. 53).

Os movimentos e partidos políticos citados mobilizaram um conjunto de notícias falsas ao recortarem trechos de publicações e documentos com informações distorcidas, tanto naquilo que diz respeito à Lei Rouanet quanto ao trabalho dos artistas. Os recortes foram descontextualizados para a composição dos ataques e a vinculação dessas produções artísticas a discursos de um perfil de arte degenerada que, numa associação mais longínqua, remete, inclusive, à propaganda nazista.

É nesse sentido que destacamos o conceito de Artivismo, o qual compreende o hibridismo arte-política, ou arte-ativismo. As pesquisadoras Stubs e Lessa, juntamente com Teixeira-Filho (2018, p. 02), explicam que nesse posicionamento, tomado pelos artistas e por sua estética, "figuram formas e modos possíveis de relações ético-políticas que podemos estabelecer com nossos corpos: para além das designações discursivas hetero-euro-andro centradas [...]”, mobilizando processos de subjetivação, do cuidado de si, criando multiplicidades e inquietações, questionando práticas normalizadoras e identitárias.

Nessa direção, Eduardo Srur, artista plástico paulistano, movimentou o Congresso Nacional em 2011 e fez reverberar a necessidade de um novo olhar para a sustentabilidade com a obra "A Arte Salva", É pertinente retomar esse ato podendo têlo como acontecimento discursivo, já que o enunciado estampado em boias salva-vidas foi e é frequentemente reatualizado, migrando das artes enquanto importante mecanismo para se pensar nas condições do meio ambiente a refletir e a tocar inúmeras outras problemáticas. Dessa maneira, A Arte Salva apareceu em hashtags, \#sóaartesalva, e em movimentos em prol da arte, tonando-se uma potente ferramenta capaz de gerar transformação(ões).

\footnotetext{
${ }^{7}$ A coluna do Pro coletivo, disponível no Metro Jornal (On-line), publicou sobre Srur: “O artista plástico paulistano Eduardo Srur conversou com o Pro Coletivo sobre mobilidade urbana, sustentabilidade e a consciência coletiva para melhorar o planeta." Disponível em: <https://www.metrojornal.com.br/colunistas/2020/06/04/a-arte-salva.html>.
} 
Inclusive, houve a irrupção desse enunciado atrelada à poesia de Zélia Duncan, "Vida em branco", publicada em seu perfil social do Instagram, no dia 08 de janeiro de 2020. Em relação aos versos publicados pela cantora, compositora e atriz brasileira, inicialmente em vídeo, nota-se que estão inseridos em um dado momento histórico, o qual foi brevemente descrito anteriormente em forma de acontecimentos concernentes à arte e a polêmicas que envolvem a atual Secretaria Especial da Cultura:

\author{
VIDA EM BRANCO \\ Você não precisa de \\ artistas?! \\ Então me devolve os \\ momentos bons. \\ Os versos roubados de nós. \\ As cores do seu caminho. \\ Arranca o rádio do seu carro. \\ Destrói a caixa de som. \\ Joga fora os instrumentos. \\ E todos aqueles quadros. \\ Deixa as paredes em branco. \\ Assim como a sua cabeça. \\ Seu céu de cimento. \\ Silêncio cheio de ódio. \\ Armas para dormir. \\ Nenhuma canção pra ninar.
}

\author{
E suas crianças em guarda, \\ esperando a hora incerta \\ para mandar ou receber \\ rajadas. \\ Você não precisa de \\ artistas?! \\ Então fecha os olhos. \\ Mora no breu. \\ Esquece o que a arte te deu. \\ Finge que não te deu nada. \\ Nem um som, nem uma cor, \\ nem uma flor na sua blusa. \\ Nem Van Gogh, nem Tom \\ Jobim, \\ nem um Gonzaga, nem \\ Diadorim.
}

\author{
Você vai rimar com \\ números. \\ Vai dormir com raiva \\ e acordar sem sonhos, sem \\ nada. \\ E esse vazio no seu peito \\ não tem refrão pra dar jeito, \\ não tem balé para bailar. \\ Você não precisa de \\ artistas?! \\ Então, nos perca de vista. \\ Nos deixe de fora \\ desse seu mundo perverso, \\ sem graça, sem alma \\ (DUNCAN, 2020, [s.p.]).
}

"Só a Arte Salva" e "Vida em Branco" surgem como rupturas, como descontinuidades de uma regularidade que, apoiada em instituições maiores, visa sufocar e padronizar os mais diversos modos de subjetivação. Especialmente acerca da poesia de Duncan (2020), vê-se funcionando como uma resposta, e com um discurso de resistência a todos os ataques explícitos à arte e aos artistas no Brasil. O videopoema viralizou em diversas outras plataformas sociais, como Facebook e Twitter, bem como foi manchete em portais de notícias, entre eles, a Revista Fórum e a Revista Cifras.

Esses veículos de informação, já em suas manchetes, expõem que a publicação da artista objetiva "defender artistas de críticas" (MIRANDA, 2020, [s.p.]) e que, ainda, "parece ser dirigido de encomenda à perseguição e ao pouco caso que o governo Bolsonaro tem com artistas" (BITTENCOURT, 2020, [s.p.]). Nota-se, portanto, como as novas concepções colocadas como verdade absoluta por um governo autoritário, as quais percorrem diversos setores públicos, sustentam e regularizam a irrupção de enunciados possíveis, dando visibilidade a determinadas práticas e à produção de determinados discursos.

Observamos, a partir do compartilhamento do videopoema nas redes sociais, regularidades enunciativas daqueles que defendem a atual política do governo, que além 
de se expressarem veementemente contra as manifestações artísticas, por acreditarem no desvio de verbas públicas, recorrem a discursos religiosos ("A verdadeira arte é a Divina"), machistas e homofóbicos, atacando diretamente a opção sexual de Duncan e sua própria aparência, assim como discursos que remetem à perversão e à degeneração das artes. Sob esse espectro, há o que Foucault (2005b) caracterizou como um éthos, um estilo, que envolve acontecimentos, práticas, discursos, instituições políticas, tecnologias, assim como foi o caso da Aufklärung, "como uma escolha voluntária de uma maneira de pensar e de sentir, de agir e conduzir-se, como marca de pertencimento e como tarefa" (CASTRO, 2016, p. 154).

A crença em uma arte que é promíscua, atentado à 'família de bem' é pertinentemente reforçada por instituições do campo educacional, cultural e dos Direitos Humanos; e recorremos ao emprego lexical 'pertinentemente' em vista das práticas atreladas às relações de poder que visam coibir, regular e disciplinar todos os corpos, os gestos, as falas, os nomes; que visam torná-los dóceis e "sem graça, sem alma" (DUNCAN, 2020, [s.p.]). Sendo assim, os fatos históricos supramencionados compõem um cenário singular para a existência de sequências enunciativas específicas. Trata-se da inter-relação entre o discursivo e o não discursivo, dessas práticas sociais e dos aparelhos reguladores do Estado, atrelados ao enunciado, ao acontecimento discursivo e suas redes.

No poema, pode-se visualizar um lugar de sujeito historicamente produzido que aciona, de forma inventiva e criativa, um discurso de resistência às práticas conservadoras construídas sobre a arte brasileira. Se nos discursos de grupos conservadores, conforme citamos, encontram-se formas de ver e falar próprias, no poema de Duncan se vê uma demarcação que, conforme Deleuze (2019, p. 20), delimita a "posição do escritor numa sociedade", o lugar da arte e do artista capaz de problematizar os processos de captura e formatação das subjetividades, também delimitados por formas de ver e falar especificas. O poema convida leitores e leitoras a (re)pensar sobre a importância da arte na formação de subjetividades capazes de questionar o discurso neoliberal que só valoriza números e resultados, em prol de modos de vida abertos ao sonho, ao deleite e aos prazeres e estranhamentos promovidos pela arte.

\section{Considerações Finais}


Em vista das pontuações aqui efetuadas, verifica-se que o vasto trabalho de Michel Foucault, desde quando se dedicou a entender a formação das ciências humanas e da prática das ciências empíricas, os processos de subjetivação e objetivação, cujas práticas da psiquiatria, da medicina clínica e do direito penal foram particularmente pensadas, até quando refletiu sobre o sujeito em um constante cuidado de si, afetou e ainda afeta drasticamente a maneira de se pensar os estratos, ou as formações históricas, que, até então, a história tradicional se preocupava em assegurar a 'linearidade' dos fatos.

As contribuições do pensamento foucaultiano aos estudos da linguagem acionam o que ele chama, em "O que são as Luzes?", de uma "reflexão histórico-crítica" (FOUCAULT, 2005b, p. 351) que possibilita problematizar e ir além das universalidades e das generalidades. Consiste, sobretudo, em uma potência que movimenta os estratos, buscando nas práticas, no visível e no dizível, no a priori histórico do arquivo, como um acontecimento foi possível, como algo pôde ser enunciado naquele momento e não em outro, como as práticas puderam transformar o sujeito em objeto de conhecimento, enfim, envolve descrever, buscar e 'sacudir' as práticas concretas e as nossas relações com as coisas e com os outros.

Não se trata de desvendar ou de olhar atrás das cortinas a fim de encontrar algo oculto ou sigiloso, mas de cartografar, de construir tramas possíveis que captem, através das regularidades, as (des)continuidades que constituíram e que tornaram possíveis que acontecimentos discursivos emergissem. É nesse sentido que pudemos, num gesto de descrever, pensar sobre as condições de emergência do enunciado "A Arte Salva" e do videopoema de Zélia Duncan, "Vida em Branco" (2020), na qualidade de acontecimento discursivo: entre jogos de verdade, do que é verdadeiro ou falso, de saber-poder movimentados pelos dispositivos e pelas práticas não discursivas e discursivas, enunciados e discursos irromperam num cenário e momento específicos.

O livro “A Arqueologia do Saber”, ponto de partida desta discussão, ao mesmo tempo em que é considerado como um ponto de deslocamento nos estudos de Michel Foucault, qualifica-se como um trabalho de revisão metodológica, sobretudo pelo tom e proposta de reflexão em relação às pesquisas precedentes. Nesse livro, encontram-se as discussões e problematizações em relação à análise arqueológica dos discursos, bem como as inflexões que sustentarão futuros trabalhos no período genealógico e nas pesquisas sobre a analítica do poder, conforme foi apresentado. Em diversos momentos de suas pesquisas, Foucault procura apresentar, com cuidado e precisão, quais eram os 
caminhos metodológicos que o conduziram à determinada reflexão. Tal procedimento aparecerá em diversos textos ${ }^{8}$, nos quais se percebe uma espécie de retrospectiva e um balanço crítico dos caminhos trilhados. Por esse motivo, e em diálogo com Nietzsche, citado por Alvim (2011, p. 73), pode-se afirmar que "as compreensões mais valiosas são criadas tardiamente, as compreensões mais valiosas são os métodos”.

\section{Referências}

ALBUQUERQUE JÚNIOR, D. M. Prefácio: Diz positivo: entre o castor e a aranha. In: FERNANDES JÚNIOR, A; SOUSA, K. M. Dispositivos de poder em Foucault: práticas e discursos da atualidade. 2. ed. Catalão: Editora Letras do Cerrado, 2017. p. 7 12.

ALVIM, D. M. Foucault e Deleuze: deserção, micropolíticas, resistências. Tese (Doutorado em Filosofia) - Pós-Graduação Strictu Senso em Filosofia, Pontifícia Universidade Católica de São Paulo, São Paulo, 2011.

BITTENCOURT, J. Zélia Duncan viraliza com vídeo onde pede a arte de volta aos que não precisam de artistas. Revista Fórum, São Paulo, 09 jan. 2020. Disponível em: $<$ https://revistaforum.com.br/cultura/zelia-duncan-viraliza-com-video-onde-pede-a-artede-volta-aos-que-nao-precisam-de-artistas/>. Acesso em: 20 jun. 2020.

CASTRO, E. Vocabulário de Foucault: um percurso pelos seus temas, conceitos e autores (Trad. Ingrid Müller Xavier). 2. ed. Belo Horizonte: Autêntica Editora, 2016.

COURTINE, J. Decifrar o corpo: pensar com Foucault (Trad. Francisco Morás). Petrópolis, RJ: Vozes, 2013.

DELEUZE, G. Michel Foucault: as formações históricas (Trad. Cláudio Medeiros e Marcio A. Marino). São Paulo: Editora N-1; Editora Filosófica Politéia, 2017.

Foucault (Trad. Claudia Sant'Anna Martins). São Paulo: Brasiliense, 2019.

DELEUZE, G.; GUATTARI, F. Mil platôs: capitalismo e esquizofrenia 2 (Trad. Suely Rolnik), v. 4. 2. ed. São Paulo: Editora 34, 2012.

DUNCAN, Z. Vida em branco. 2020. (1m18s). Disponível em:

<https://www.youtube.com/watch?v=IjV-99mZ8eM>. Acesso em: 22 jun. 2020.

FERNANDES JÚNIOR. A. Michel Foucault. Discurso, história e construção de singularidades. In: MELO, S. M.; FERNANDES, C. A. Violência e seus paradoxos: práticas discursivas pelas lentes de Michel Foucault. São Carlos: Edufscar, 2016. p. 0920.

FISHER, R. M. B. Adolescência em discurso: mídia e produção de subjetividade. Tese (Doutorado em Educação) - Programa de Pós-Graduação em Educação, Universidade Federal do Rio Grande do Sul, Porto Alegre, 1996.

FOUCAULT, M. As palavras e as coisas: uma arqueologia das ciências humanas (Trad. Salma Tannus Muchail). 8. ed. São Paulo: Martins Fontes, 1999.

Arqueologia das ciências e história dos sistemas de pensamentos (Org. Manoel Barros da Motta) (Trad. Elisa Monteiro). 2. ed. Rio de Janeiro: Forense Universitária, 2005a.

\footnotetext{
${ }^{8}$ Para citar um exemplo, destacamos o texto "O sujeito e o poder", em Michel Foucault: uma trajetória filosófica - para além do estruturalismo e da hermenêutica (2010), de Dreyfus e Rabinow.
} 
O que são as Luzes? In:

Ditos e Escritos II: Arqueologia das Ciências e

História dos Sistemas de Pensamento (Trad. Elisa Monteiro). Rio de Janeiro: Forense Universitária, 2005b.

Aulas sobre a vontade de saber: curso no Collège de France (Trad. Rosemary Costhek Abílio). 1. ed. São Paulo: Martins Fontes, 2014.

A Arqueologia do Saber (Trad. Luiz Felipe Baeta Neves). 8. ed. Rio de Janeiro: Forense Universitária, 2016.

Microfísica do poder (Org. Roberto Machado). 6. ed. Rio de Janeiro/São Paulo: Paz e Terra, 2017.

GREGOLIN, M. R. O enunciado e o arquivo: Foucault (entre)vistas. In: SARGENTINI, V; NAVARRO-BARBOSA, P. Michel Foucault e os domínios da linguagem. São Carlos: Claraluz, 2004. p. 23-44.

Foucault e Pêcheux na análise do discurso: diálogos e duelos. 2 ed. São Carlos: Claraluz, 2006.

MIRANDA, I. Zélia Duncan viraliza com poema em que defende artistas de críticas. Revista Cifras, 09 jan. 2020, intitulada. Disponível em: $<$ https://revista.cifras.com.br/noticia/zelia-duncan-poema-artistas>. Acesso em: 20 jun. 2020.

ORLANDI, L. B. L. Do enunciado em Foucault à teoria da multiplicidade em Deleuze. In: TRONCA, I. A. (Org). Foucault vivo. Campinas: Pontes, 1987. p. 11-42.

SCHÄFER, G.; LEIVAS, P. G. C.; SANTOS, R. H. Discurso de ódio: Da abordagem conceitual ao discurso parlamentar. Revista de Informação Legislativa, Brasília a. 52, n. 207, p 143-158, jul./set. 2015. Disponível em:

<https://www12.senado.leg.br/ril/edicoes/52/207/ril_v52_n207_p143.pdf >. Acesso em: 26 set. 2019.

STUBS, R.; TEIXEIRA-FILHO, F. S.; LESSA, P. Artivismo, estética feminista e produção de subjetividade. Revista Estudos Feministas, Florianópolis, vol. 26, n. 2, p. 1-19, 2018. Disponível em: <https://www.scielo.br/pdf/ref/v26n2/1806-9584-ref-2602-e38901.pdf>. Acesso em: 27 jun. 2020.

VEYNE, P. Foucault: o pensamento, a pessoa (Trad. Luís Lima). Lisboa: Texto \& Grafia, 2009. 